\title{
Organisational Prototyping: Adopting CSCW Applications in Organisations
}

\author{
JAKOB E. BARDRAM \\ Computer Science Department, Aarhus University, Denmark \\ bardram@daimi.aau.dk \\ "[A] particularly central aspect of \\ implementing groupware is ensuring that \\ prospective users have an appropriate \\ understanding of the technology, that is, \\ that their technological frames reflect a \\ perception of the technology as a collective \\ rather than a personal tool."
}

- Orlikowski 1992, p. 368

\begin{abstract}
The usefulness of applications which support cooperative work depends in its very nature on the way the cooperative work practice is organised. At the same time, the adoption of new technology is difficult and complex because of the amount of people involved and their distribution in time and space. This paper explores the possibilities of addressing this adoption process in a more simplified, yet systematic way without losing the focus on the interdependencies which characterise cooperative work. The notion of adoption is discussed as a dual process of adapting both the computer support to the work and adapting the work to the computer. A method called organisational prototyping is presented which aims at facilitating this adoption process. A case illustrates how organisational prototyping was used in the adoption of a cooperative tool for managing projects within a large engineering company in Denmark.
\end{abstract}

Keywords: Organisational Prototyping, Adoption, Computer Supported Cooperative Work.

\section{Introduction}

Within the field of CSCW it has been widely recognised that the acceptance of a system is very sensitive to the way in which it is introduced into an organisation (Erhlich 1987, Grudin 1994). The process of adopting a computer application 
meant to support cooperative work often implies changing the work practices in order to fully utilise its new potentials. Orlikowski (1992) gives an excellent example of how the cultural aspect of work practice must be taken into consideration to ensure a successful adoption of a CSCW application. Orlikowski raises the general question of "how to anticipate the required structural and cognitive changes when the technology is brand new" (p. 368). This paper provides a method for addressing this question.

Okamura et al. (1994) answer the question by suggesting the use of mediators, that is individuals who deliberately intervene with organisational authorisation in the ongoing use of CSCW technology. In this respect, "these mediators adapt a new collaborative technology to a context, modify the context as appropriate to accommodate use of the technology and support ongoing changes to the technology and context over time" (p. 56). These mediators can be very useful in introducing new technologies to an organisation, as described by Okamura et al. But having mediators stand between developers and users may not always be useful. Because these mediators lack a deeper knowledge of the workplace, they may be insensitive to important aspects of how to organise the work (e.g., the way related tasks are handled and social dynamics in the workplace) (Grudin 1994). At the same time the interests and motives are not necessarily the same for the mediator and the users, thereby leaving behind a clarification of who is responsible for reorganising the work.

Grudin \& Palen (1995) found that 'evangelists', as such mediators can be characterised, did not explain the adoption of a groupware technology within the organisations they studied. Instead, they found widespread reports on peer pressure where the adoption spread according to a bottom-up pattern. Thus, groupware can succeed without managerial mandate. Helped by the technological feature of the application it can attract a critical mass of users, after which a social pressure by peers and others extends the use into an organisation. From a design perspective, ensuring that users gradually adopt the system by providing flexible technological features seems to be generally advocated. As stated by Kreifelts et al. (1993): "we would like to have coordination systems that encourage self-organisation of cooperative work by the end-users themselves" (p. 33).

However, this strategy of relying on technological features to encourage a critical mass of people to use the system raises two questions: Firstly, how can the use of the computer system within a specific work environment be organised. Even when the adoption is spreading bottom-up, the future use of a computer system has to be established within the overall work practices at some point in the process. This means that issues of establishing a division of labour, responsibility, procedures for general use and error handling, etc. have to be addressed and socially agreed upon within the work setting. Secondly, how can we from a design perspective establish which features will mediate the acceptance of the technology within an organisation. In other words, how do we establish the functionality and central ideas of the computer system and how can computer support for cooperative work be designed and evaluated in the development process. Even when adopting standard groupware technology, the issue of design is important. The technological features of groupware systems are not static, but often need to be tailored according to the different preferences and constraints within a work setting. The 
notion of tailorable and flexible computer tools which do not enforce rigid ways of performing work supported by a computer has been strongly emphasised within CSCW (Trigg and Bødker, 1994). The use of such flexible tools has be organised within the specific work environment which they are to support, and the tool has to be tailored (i.e. designed) according to this organisation of work.

In this paper the process of adopting a CSCW tool in a work setting is discussed as a dual process of both adapting the organisation of work to the conditions of the tool, and adapting the tool to meet this organisation of work. The case reported here shows how a participatory design method, which we have chosen to call 'organisational prototyping', facilitated this two-way process of adopting a CSCW application within a social organisation of work. By applying organisational prototyping in the design of computer support for the collaborative activity of project management, the possibilities and constraints of such a tool were examined. By both addressing the design of the tool and it's use within the work practices of project mangment, organisational prototyping facilitated a process of both adapting the tool, and changing the organisation of work according to the conditions of the tool.

\section{The Project Manager}

The Project Manager was developed in close cooperation with the managers of a large engineering company, Delta Corporation (a pseudonym), which manufactures components for oil-burners, such as oil-pumps, nozzles and ignition units. A group of seven top-managers and two designers developed a prototype for a project management system during a period of 8 months. The project had a clear design objective aiming to investigate the possibilities of developing a tool to support the collaborative task of managing projects, and therefore we did not use any of the standard software packages for project management available on the market. As a research project, the project ended after the period, and the project manager remained a prototype.

The requirement for the Project Manager was explored during a participatory design process applying qualitative interviews, observations, future workshops, and prototyping (for a description of the design methods mentioned, see e.g. Greenbaum \& Kyng 1991). Furthermore, the different artefacts, and how these artefacts were applied in managing projects were studied. These artefacts included paper-based forms, bar charts and a computer-based system.

\subsection{The background of the Project Manager}

Basically, there were two kinds of projects at Delta: development of new products and modification to old ones. Both types were typically initiated by customer demands. Projects could vary from small projects involving a single employee during a week, to very large projects involving 20-30 employees lasting up to two years. Managing projects was a central activity at Delta done primarily by coordinating sub-activities at different management meetings and filling in paperbased forms. A previous attempt to support this activity was a computer-based system provided by the central computer department at Delta. This system supported registration of the economic goals and spending of a project, and served 
primarily as an accounting system oriented toward the financial history of the project. The system did not support the creative planning and coordination of future activities, which was the main challenge of managing projects. Filling in all the details on expenses of a project became an extra work load which did not help keeping track of future activities in the project. The system was rejected after a period of use, and Delta returned to manage its projects through meetings and standard paper forms.

The analysis of project management at Delta became the input for a future workshop which revealed three central problems: There was a lack of structure in handling projects, something which the management at Delta perceived as vital for improved project handling. Projects were handled in a very ad hoc fashion at the meetings. Some were discussed because of breakdowns, others because of questions from impatient customers, and still others because of an inquiry from one of the managers wanting to know "What is going on?". This way of handling projects led to a lack of overview, both a general overview of all the active projects and the relations between them, and an overview within the individual project which could last several months and involve many different people. Finally, there was the problem of determining the priority of the projects, which was difficult because of the lack of overview and the ad hoc nature of the project handling at Delta.

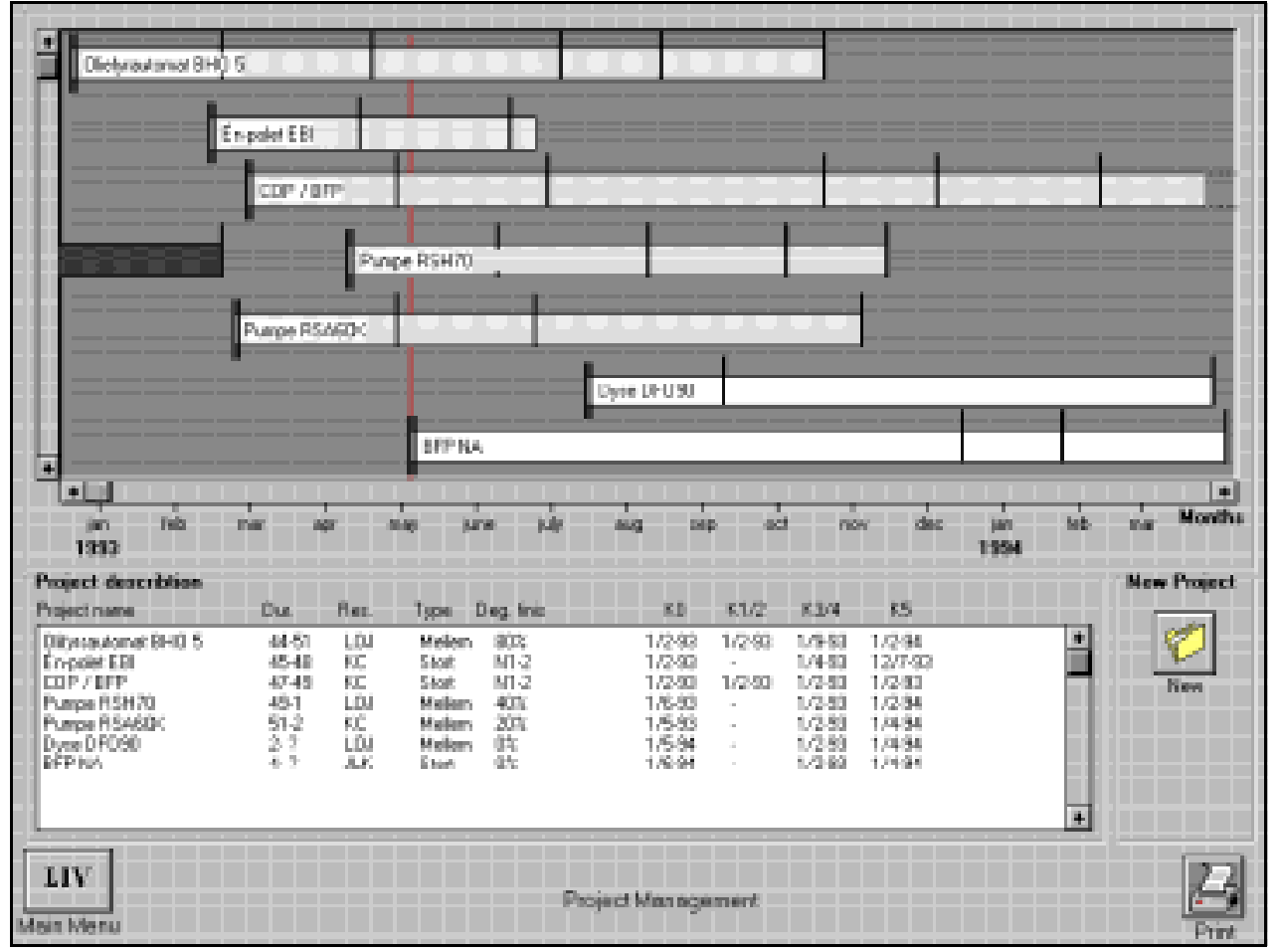

Figure 1. The project list

Combining the experiences of using the old system and the three central problems in handling projects at Delta, it was possible to list three demands for a computerbased tool supporting the management of projects: 
- The tool had to support communication. The coordination of activities in the projects was central to project management. This was done at various project meetings at which the different managers and their departments made commitments and agreements to handle different parts and activities in the project within certain resource limits (time, money, staff, tools and machinery, etc.)

- The tool should provide an overview of the projects, both within individual projects and between all projects. This overview should also support the process of prioritising the projects when necessary.

- The tool had to be simple with a visual representation of the status and with a minimum of inputs. This demand was primarily due to the experience with the old system.

These three demands were working against each other. For instance, in order to make a correct priority the managers must know the resource bottlenecks. The overview is not complete if the demand for, and use of, resources is lacking. But registration of the use and allocation of resources to a project could make project management a very cumbersome task, as in the old system. Another problem is maintaining an overview of communication. The volume of notes, requests, answers, etc. in a project can take on enormous dimensions. Keeping an overview in all the recorded communication in a project would be impossible.

A prototype for a Project Manager was constructed through several iterations trying to resolve these contrasting demands. The following section describes the final version.

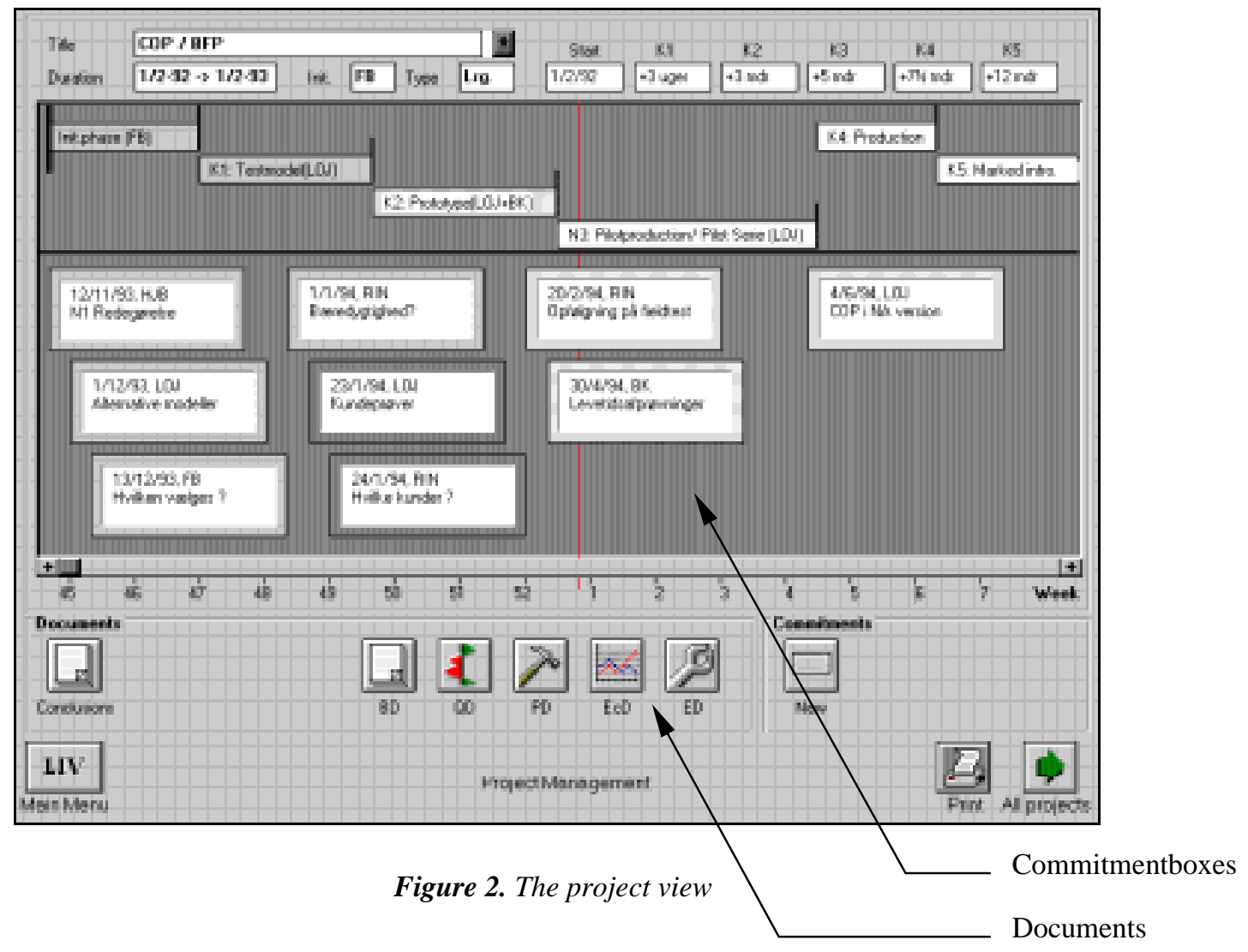




\subsection{The basic concepts of the Project Manager.}

Basically, the Project Manager is divided into two views: One view provides a list of all the projects at Delta, and the other presents a view of each individual project. The project list (figure 1) gives an overview of all current, completed and future planned projects. This is done through a graphical representation of the temporal order of the projects (Gantt chart) and a textual list of the most important attributes: project name, duration, person responsible, project type, degree of completion and the different key points in the project. The projects can be sorted according to the different characteristics of a project: date of expiration, responsible person, type, etc. Colours are used to indicate the temporal status of the project, like red for delayed, light brown for terminated, etc.

In most cases, the project list will suffice to give the overview needed, but more detailed information on a project can be obtained from the project view (figure 2). The uppermost part of the project view displays the attributes of the project. The bars have the same colour coding as the ones in the project list. In addition to this more traditional temporal overview, the project view also gives an overview of and access to the communication concerning the project. This is done through commitment boxes and the document icons placed in the lower part of the project view.

The commitment boxes can contain any kind of relevant communication between involved persons in the project. This includes requests, offers, status reports, promises, commitments, notes of interest, answers to all these, etc. Hence, the boxes are open for any kind of communication, even communication not related to the project. The form of these messages is very similar to ordinary email with a date, a sender, a subject and some free text, except that the 'receiver' is the specific project.

The document icons represent hyperlinks to documents and drawings attached to a project. They are accessible for editing in the word processor and the CAD system used at Delta. These documents are the same as the paper-based ones previously made during a project and have been divided historically into five categories of reports: business potentials (BD), quality (QD), production (PD), economics and budget $(\mathrm{EcD})$, and engineering (ED). The 'conclusion document' contains an automatically updated overview over the latest conclusions from the other five documents.

\section{Organisational Prototyping}

A clear shortcoming of the traditional use of prototypes is the focus on individual use of an application in terms of functionality and user interface of the tool. Prototyping sessions seldomly touch upon the cooperative context in which the tool is to be used in the future. This reflects that the evaluation process of CSCW systems is more complex than that of single user applications (Grudin, 1994). Evaluation and design for cooperative work settings can be remarkably time consuming, due to the number of people involved, because most cooperative work unfolds over days and weeks, and because it is distributed across several sites. There is a variability of group composition and a range of environmental factors, which all are important factors in determining how the tool should be designed and applied within a work setting. As the purpose of CSCW applications is to support 
the mutual dependencies of the actors involved in cooperative work, distributed in time and place, this complexity seems unavoidable (see e.g. the work done in the COMIC project; COMIC D2.1 1993). This could lead to a rejection of using incomplete prototypes and mock-ups, because it would be impossible to observe and evaluate the cooperative work, involving several persons over a longer period of time based on an incomplete prototype.

However, a method for designing and evaluating the usefulness of a computer tool which supports collaborative work was developed in the project at Delta. The method shows that the concern for increased difficulties of evaluating prototypes in collaborative work practices might not always be true. We have chosen to call this participative design session 'organisational prototyping' according to the two main inspirations for the method: organisational games (Ehn and Sjögren, 1991) and cooperative prototyping (Grønbæk, 1991; Bødker and Grønbæk, 1991).

\subsection{The components of organisational prototyping}

The adoption process mediated through the organisational prototyping is defined as a dual process of both adapting the tool to the organisation and adapting the work practice to the conditions of the tool. The organisational game, as described by Ehn and Sjögren, is based on the assumption that the basic problem in the domain is not technology driven but a question of organisational change and education. However, to maintain the relationship between future organisation of work and the design of the tool supposed to support this work, the method of organisational prototyping involves a more technical focus by involving a prototype in the game. The idea is to bring people together, whose collaborative work is normally distributed in time and space, and initiate a discussion of new ways to organise work and of the technological opportunities and constraints of supporting this work by computers. The session should simulate realistic situations from the participants' daily work, trying to sustain positive aspects of the organisation of work, and at the same time clarify and improve problematic aspects.

The components of organisational prototyping are the following: (i) As a prologue to the session one or more scenarios are introducing the prototype to the work practice in question. Based on earlier analysis and investigations the prototype is designed according to certain ideas addressing certain problems and needs within the organisation. The scenario describes how the prototype can mediate the work and thus situates the prototype within the work practice. A central component of organisational prototyping is of course (ii) the prototype itself, containing realistic test data and providing enough functionality to illustrate and act out the different scenarios. When the session is started, the main component are (iii) the situation cards which introduce prototypical examples of breakdown situations. The situation cards are intended to resemble typical events and problems occurring in daily work. The cards are stacked in a pile in the middle of the participants, who draw a card on turn, read it aloud and start discussing how the problems introduced by the card can be handled. These cards are produced beforehand by the conductors of the session, based on investigations into work practices and typical problems within the organisation. In resolving the breakdowns introduced by the situation cards the participants are making commitments to solve the problems and 


\begin{abstract}
Starting a project: After several enquiries from customers, a decision is made to make a new type of pump. This decision is made at a project meeting. An idea phase is initiated, involving the sales manager, the production manager and the quality manager along with some of their employees. This phase is to reveal whether the pump is feasible and technologically possible. The project is represented in the Project Manager, and a deadline for the idea phase is set. If a decision is made to develop the pump, the rest of the project will be planned when this phase is over. This decision is represented by a commitment box, and at the same time the three involved managers make a commitment to fill in the FD report represented by another commitment box.

Making changes to a commitment/deadline: At a project meeting it is discussed whether the deadline for the initial prototype of the RSA pump must be postponed, because a key constructor is occupied with another project. After looking at the other projects, it is decided that the project, on which the constructor is currently working, has a higher priority. This decision is represented in the Project Manager by dragging the marker that ends the phase for the initial prototype for the RSA pump and by creating a commitment box explaining the decision of postponing the project. Another commitment box, which describes the activities which will solve the problem (e.g. transferring the constructor to work on the RSA pump at a certain date), is also made.

Follow up on a commitment: When one of the activities represented in a commitment box is completed, the person responsible uses the Project Manager to describe the result and marks the commitment box as 'done'. This change is distributed to the other PCs in the network.

Preparation for the project meeting: When the product manager prepares for the project meeting, he makes a list of all the projects in which he is involved from the project list view. If a project needs special attention (e.g. one which is coloured red), he can go into the project view and inspect the different commitments within the project and thus remind himself of the conditions for the project.

Having project meetings: A PC running the Project Manager is located in the meeting room, providing a point of reference when it is necessary to check commitments or documents. All decisions made at a meeting are put into the Project Manager right away, but sometimes it is necessary to have the secretary fill in all the details later.
\end{abstract}

Figure 3: Scenarios for using the Project Manager

the conditions for each commitment are discussed. These commitments and their conditions are formulated in an (iv) action plan for each situation card. An action plan answers the questions of 'who will do what, where, when, why, and by which means.' Furthermore, the individual commitments made are noted in (v) a role script for each participant. Finally, the last component of organisational prototyping is (vi) the playground, which is used to save and categorise the resolved situation cards and their attached actions plans. The playground can be divided according to different work tasks, or it can be organised according to possibilities of changing either the computer system or the organisational setting. The outcome of an organisational prototyping session is modified and new scenarios, suggestions for redesign to the prototype, the role scripts for each participant, and the action plans for each situation card attached to the playground. The next section will illustrate how these components of organisational prototyping were produced and applied at Delta. 


\section{Organisational prototyping at Delta}

The organisational prototyping session at Delta was set up to simulate project management as it was done at Delta, that is through meetings, use of phones and documents. The Project Manager was to assist this work as a tool for distributing messages and providing an overview of the different projects. The scenarios for using the Project Manager are illustrated in figure 3. These scenarios illustrate the outcome of the organisational prototyping session.

The situation cards were made on the basis of old project documentation and by interviewing different people about typical problems in project management. Six fictitious projects of different size, time schedule, complexity and objectives were made and represented in the Project Manager. This enabled the participants to assess the usefulness of the tool in resolving the events and breakdowns introduced by the cards. Hence, they were asked to play their normal professional roles and to make commitments to breakdowns as they would at an ordinary project meeting. The conditions for each commitment were discussed, and an action plan for solving the breakdown situation was formulated. Part of these action plans were initiated or carried out through the use of the Project Manager which was used all through the session. This placed the tool in a (simulated) work practice and thereby into a context of use. The action plans, their conditions and commitments for handling different breakdown situations were written down and put on a bulletin board representing the playground. In organisational games the playground is normally divided into the different tasks involved in the work in question. At Delta, however, the playground was divided according to the kind of changes needed to be implemented by the end of the session. These categories were made according to whether the action plan could be realised (i) with the Project Manager, (ii) without it, (iii) with a redesigned or extended version of it, or (iv) with organisational changes in Delta. An action plan could be placed in several categories.

The organisational prototyping at Delta took a total of 5 hours which is considerably shorter than the organisational game described by Ehn \& Sjögren. Nevertheless, it was still possible for the users to become aware of the technical and organisational requirements for making the Project Manager work successfully within Delta. The session was video-recorded, and by quoting ${ }^{1}$ and analysing five episodes, it is illustrated how (i) the tool was adapted to support the task of project management, and how (ii) the participants during the game became aware of the role of the Project Manager within this task. Hence, the outcome of the organisational prototyping at Delta was both a clarification of the potentials and problems of the Project Manager, as well as a positioning of the tool within the overall work project of project management.

The seven participants are identified by their professional roles: HM: Head Manager, PM1: Production Manager 1, PM2: Production Manager 2, SM: Sales Manager, EM: Economic Manager, QM: Quality Manager, PM: Purchasing Manager. The designers are identified by $\mathrm{D}$. 


\subsection{Adapting the tool to the work practice}

The organisational prototyping session addressed how the prototype should be adapted or redesigned in order to support the collaborative work. The session revealed problems and opportunities of supporting the overall work, but did not address the individual use of it. The following two episodes from the session illustrate how the Project Manager was developed to support the handling of commitments, and how a completely new type of computer support, an electronic bulletin board, was introduced during the session.

Episode 1: How the idea of commitment boxes came about.

[We enter the session when there is a discussion on how to use the commitment boxes which were introduced in the session as 'message boxes' for general purposes]

PM1. Today we describe it [the commitments made to a project, deadlines agreed upon, etc.] in the minutes of the meeting where these agreements were made....

D. That can be done here [in the Project Manager]. When a message box is made, detailed information can be added afterwards. This could be any kind of description. [Enters a text to illustrate the point].

EM. Yes -- that could be done instead of the minutes. Then we would keep everything together in there [in the Project Manager]. It must be able to contain such minutes of commitments made to the projects. Then we can have an overview of that also ... That would surely be useful.

Episode 2: Invention of the meeting bulletin board.

[The discussion of how to use the message boxes continues]

EM: If we had production meetings on a regular basis we could probably use them [the message boxes] to ensure that certain issues were addressed. That is, not to put up a message about 'remember to do that', but a message which reminds us to address the issue on the meeting. Then, when we go to these meetings I'll assume that you take a look at this [the Project Manager] before the meeting. Then you're sure you've seen it [the message], and know that it is going to be addressed at the meeting. That is a good way of using them [the message boxes] if that's what is meant by the word 'message'.

[Approx. a hour later ...]

HM. I've got an idea. We have these product meetings every Monday where we try to go through all our products looking at economics, sales, production, and all those things. Couldn't we have a -- shall we call it a 'reminder board' for these meetings. If there is a question concerning a pump you would like to discuss at the next meeting, then you write a little yellow note and stick it to the bulletin board concerning pumps. Then everybody would immediately know that this is an issue we need to address and discuss at the meeting ...

Given that communication was central to project management a recurrent theme in the organisational prototyping session was how to use the message boxes. The episodes illustrate how the participants start by suggesting changing the use of the existing design and end up generating a completely new idea of using an electronic bulletin board for the meetings. There was a need for distinguishing between different kinds of communication concerning project management: on the one hand commitments mutually agreed upon, and on the other hand more loose and 
informal communication like questions and messages. This is achieved through redesigning the project manager to include commitment boxes in the project view and an electronic bulletin board for other kinds of messages concerning projects.

Finally, the two episodes illustrate how new ideas and innovations to the design are generated through a discussion in which all participants, including the designers, contribute. For example, in the second episode the idea of a bulletin board looks as if it came from the Head Manager, but the idea was also discussed in the initial comment of the Economic Manager. In organisational prototyping there is a mutual influence and inspiration taking place during the discussion, which gradually leads to new ideas of computer support for the work.

\subsection{Adapting the work practice to the tool}

Through the organisational prototyping, the participants (both the managers and the designers) obtained an insight into the nature of the cooperative task of managing projects and how the Project Manager could support this work. The following three episodes illustrate how the session triggered a discussion of project management and how the organisation of work was adapted to meet and utilise the possibilities of the Project Manager.

Episode 3: The Project Manager is a supplement to the usual way of handling projects.

[PM1 is explaining how he will meet a deadline by prioritising some of the pumps]

PM1: Maybe I won't prioritise the Japanese pumps. But then I'll attend a meeting and then SM will say that he wants his [Japanese] pumps.

HM: You could call him and ask in advance.

PM1: Then we could just as well have the meeting.

HM: Wait - this [the Project Manager] can't eliminate the need for communication about everything.

PM1: No-no....

HM: It is only to maintain the overview. You still have to call SM and tell him that you are in trouble with your pumps and ask him what to do. [...] We cannot leave everything to happen through the screen.

PM1: Yes, that is true. But that means that we sometimes have to get together and have a meeting.

HM: Yes of course. It is definitely a crisis to delay a project. We'll have to sit down and unite our strength. But what we must provide in common is consensus and overview.

[......]

D: $\quad$ This message from a constructor will explain why the project is delayed. Then the problem is explained.

PM2: But - you can't get an indulgence just by typing something into the system. [By indulgence, PM2 means to be relieved from doing anything further in the case, but to type the problem into the Project Manager.]

These two dialogues explain by example how the management at Delta became aware of the Project Manager as a tool in the task of handling projects. The main tasks of communication, coordination and making commitments to certain 
activities would not be changed by the tool. Instead, it would provide an overview on time schedule, documents and communication connected to the project, which would facilitate more effective project meetings (c.f. also episode 2).

The episode illustrates how organisational prototyping adjusts the expectations to computer support. Establishing the collective use of coodination technology is not just a question of revealing new opportunities (as in espisode 1) but equally important to reveal the constraints of the tool. Organisational prototyping helps both users and designers to evaluate a computer tool in more authentic ways, not putting up unrealistic expectations to the wonder of new technology solving problems which belong to the way work are organised and coordinated.

Episode 4: How to maintain an overview.

\section{Situation card no. 6.}

The prototype for the one-pole ignition unit is not finished as scheduled. There is a message in the Project Manager from a constructor saying that the prototype is delayed for two weeks caused by 'unforeseen difficulties during the final test'. What action should be taken - if any?

[After the situation card is read, the message is shown in the Project Manager, with 'Hansen' as the sender.]

HM: That isn't up to Hansen to decide.

D: $\quad$ No - but this only illustrates that he is the one issuing the message.

EM: Well, we'll have to sit down and discuss the problem [...]

QM: $\quad$ But the question is, whether it is the constructor [Hansen] that sends that message [...]

EM: $\quad$ No-I don't think so.

QM: No, it must be PM2 [Hansen's superior manager] who must send it.

SM: Wait a minute, It is only a message. He hasn't made any changes to any deadlines.

HM: The question is whether it is interesting to know that he's behind in a project. There are maybe 20-30 people involved in a project, to take a big project. They'll all be behind at some point or another. Will they write that to us?

D: $\quad$ But if it is a firm deadline we all agree upon? An agreement to be held? [Illustrates the message in the Project Manager]

PM1: That is too detailed. It would be very confusing to have that kind of detailed information. This is a matter between PM2 and one of his employees. It has to be PM2 who gives us that information.

PM2: I don't think that it should be the employee who makes that kind of message.

PM1: We would get too much information. We would drown in information if we were to receive all that kind of small messages.

HM: If Hansen isn't responsible for the project he shouldn't be able to send messages.

The situation card reflects the initial design idea of using the boxes in the project view as message boxes. This is perceived as a very bad idea by the managers, because the communication overview would be disrupted by less important and 
irrelevant messages and requests. It was decided that the boxes should only be used to describe commitments (and the name was changed from 'message boxes' to "commitment boxes') and they should only be created collectively at project meetings. Because all those responsible for a project attend these meetings, a commitment from everybody is assured. This illustrates how the use of the Project Manager was adapted to the general task of handling projects without changing the design. There was no limitation to what kind of messages could be sent in the boxes built into the tool. The limits were established only in the context of use.

Episode 5: Responsibility for maintaining the overview.

\section{Situation card no. 2.}

The customer who ordered the pump RSA 60X under development becomes impatient and wants to know how far the project is and when the pump is likely to be marketed. Who does what in order to provide the customer with an answer?

[The sales manager (SM) is asked to start formulating the action plan to this question]

SM: $\quad$ That's easy. I'll look at the screen and tell him that it'll be finished in week 12. Well - then I'll probably call PMI [the manager responsible for production of pumps] to ask if he's sure, because now the customer is told. [...]

HM: No - that's not the way. We have a person responsible for customer contact. It's none of PMI's business.

$[\ldots]$

HM: It would be very unfortunate if we had to check over the telephone. If we don't trust that [pointing to the Project Manager] we should not have it. If those deadlines are not the ones we agree upon, then we should forget the whole thing [i.e. the Project Manager].

SM: You're right.

HM: Don't believe it's going to be any easier to move deadlines just because of the system.

$[\ldots]$

HM: It is dead serious [pointing to the computer].

EM: We are going to trust what's in the system - otherwise everything will be a mess.

HM: It's terribly important to say that everything that's in there is true. [...] You are allowed to assume that there is a commitment to everything there, and that it's valid.

Because the users share one view of the projects through the Project Manager, the view has to be valid. This is both a matter of trust and responsibility. If the view provided by the Project Manager cannot be trusted, there is no need for having the tool in the first place. So everyone using the Project Manager has a responsibility to maintain the overview by providing the correct information. This means keeping the documentation, the status of different activities (started, ended, delayed, etc.), and the commitments made to future activities up to date. The episode illustrates how the managers at Delta became aware of the need for discipline by everyone involved in order to maintain the Project Manager as a useful tool. 


\section{Lessons learned}

The case at Delta illustrates how the use of organisational prototyping provides a frame for adopting technology within an organisation. In this section we summarise some of our experiences with organisational prototyping as four central questions which need to be addressed when setting up the session.

Who should participate? Several considerations within prototyping literature address the question of establishing the user group for prototyping (Pape \& Thoresen, 1987; Bødker \& Grønbæk, 1991, Grønbæk, 1991). Here, it is often argued that competent user representatives have to be preferred to middle or upper management because the user has the necessary knowledge and familiarity with the daily work processes. However, when moving the objective of investigation further out into the cooperative work within an organisation and trying to reveal the usefulness of a computer system on a more overall organisational perspective, the competent user shifts towards management representatives. Management both possesses the overview on the coordination and planning aspects of work, and at the same time has the opportunity to change the way things are done, i.e. has the skill and power to implement the commitments and action plan agreed upon in the organisational prototyping session. In the case at Delta, the participants were both the future end-users and the managers of Delta. This seems to be a good arrangement for an organisational prototyping session. When looking at the session afterwards, the role of the Head Manager of summing up the discussion and turning it into constructive ideas is evident (see e.g. episode 2 and 5). This may come as no surprise, after all it is the role of a manager. Nevertheless, because organising and coordinating work is the responsibility of management it is important to have them as participants in organisational prototyping, as well as the future users. The future users, on the other hand, should be aware that organisational changes are allowed and subject for debate.

Turning to the technological side of the adoption process, it is important to have participants with a technical insight in an organisational prototyping session. In the case at Delta, the focus was on design and the designers themselves participated, and conducted the session. As illustrated in e.g. episode 1, the designers possessed the knowledge on the constraints and possibilities of the prototype enabling them to suggest how the idea of the production manager can be realised in the prototype.

When should organisational prototyping be applied? Because prototypes can be used to reveal requirements to the design and because experimentation early in a design process is cheap, the general recommendation is to use prototypes as early as possible in systems development. This recommendation is also valid for organisational prototyping and the method was applied in this way at Delta. However, organisational prototyping, when used in a design process, aims at revealing the overall organisational constraints and possibilities for computer support for cooperative work. Organisational prototyping asks the question of what the system should do within an organisation, whereas a traditional interface prototyping session addresses exactly how it should be accomplished with the computer. Therefore, organisational prototyping is to be made as one of the early 
design activities in order to uncover the overall functional requirements to the computer system. Furthermore, if the design is based on scenarios (Kyng, 1995) the scenarios produced as a result of organisational prototyping can become a guide during the further development process.

When turning to the organisational learning side of the adoption process the recommendation of using organisational prototyping early in the process is less valid. If a systems development project takes a year or more, the insights and commitments achieved during an organisational prototyping session early in the project will often be forgotten, because it has been impossible to implement them without the computer system. Thus, one or more 'deja vu sessions' might be appropriate as an implementation technique. This also addresses the use of organisational prototyping for adopting standard groupware technology within an organisation. Whether it is standard or tailor-made technology the organisational prototyping encourages a learning process which situates the computer tool within the cooperative work. An organisational prototyping session will also be suitable for tailoring the computer system to meet the organisational conditions.

To summarise, organisational prototyping is a method applicable both early in the design phase of systems development, and later when implementing the computer system into an organisation.

How should the work practice be addressed? The scenarios introducing the use of the prototype are mainly open ended descriptions of typical ways of applying the new tool within the work setting. The scenarios are essential as input to the prototyping session because they reveal to the participants the design ideas of the tool, how these ideas are intended to match the work practice, and how the tool is to be used. These scenarios are shortly presented to the participants as a prologue to the session which proceeds by applying the situation cards. An insight achieved in the case at Delta, however, was to distinguish between situation cards introducing typical events and cards introducing breakdowns - a distinction we did not made at that time. At Delta only breakdowns were introduced in the session which had the effect that the participants handled these breakdowns in the usual manner, i.e. without the Project Manager. When analysing the video-recorded session afterwards it became evident that the participants did not pay much attention to the Project Manager during the initial two hours of the session.

Our conclusion is, that these two hours might just as well have been used to act out the scenarios using the prototype. So, the recommendation is to start the organisational prototyping by simulating prototypical ways of doing work in the future with the computer support according to the scenarios. This first act of organisational prototyping is mediated by situation cards introducing typical events happening during work. The first act is intended to validate the scenarios and to evaluate the computer system within the central work practices. The second act then moves the discussion into more peripheral aspects of work by having the situation cards introduce breakdown situations. Central to cooperative prototyping is the notion of breakdowns (as used by Winograd \& Flores (1986)) as an important resource for learning about unarticulated aspects of users' work and how these aspects may affect the design of a computer system (Grønbæk, 1991). Thus, the second act is intended to situate the prototype in simulated breakdown 
situations partly to assess its usefulness in these unusual work tasks, and partly to initiate a discussion of more tacit aspects of the work practices, which have not been addressed by the scenario descriptions.

How should the prototype be applied? The recommendations of cooperative prototyping emphasise that: (i) "Users need to be actively involved in prototyping passive participation in demonstrations and unplanned evaluations of prototypes is insufficient to get benefits from prototyping", and (ii) "Unreflected and unarticulated aspects of users' work need to be considered to design good systems" (Grønbæk, 1991). Thus, to fully experience the prototype, the users need to be in control of its use for some period of time - to try it out in work-like settings (Bødker \& Grønbæk, 1991). This is equally true for organisational prototyping; the ideal organisational prototyping session involves users working together and realising their action plans via the computer. However, this raises two fundamental problems: Firstly, to avoid breakdowns caused by an incomplete prototype, the prototype needs to be implemented to a high degree. When supporting cooperative work, this also means that communication through networks, database management, etc. needs to be functioning if the users should experience the cooperation through the computer. Secondly, the users need to know how to use the computer, i.e. how to operate it, how the design of the system is represented in the interface, etc., which raises demands for an individual education of the users prior to the organisational prototyping session. Addressing these two problems requires substantial preparation of the organisational prototyping which contradicts the recommendation of using organisational prototyping early in the design process.

At Delta, it was decided to have one of the designers operate the computer in order to maintain the focus on the collective activity of managing a task and not on the operation of the Project Manager. This translation between the users' intended actions and the conditions of the tool was done primarily to avoid breakdowns caused by the lack of knowledge of the exact use of the tool and by the inadequacies of the horizontal (incomplete) prototype. This translation strategy also enabled a comparison of the intentions expressed by the participants with the possibilities of the prototype, thereby giving information on how the future tool should support the collaborative work of project management as agreed upon in the action plans.

Nevertheless, we argue that the users indeed were actively involved in a lively debate, as illustrated in the above cited episodes, despite the fact that the users had no direct 'hands-on experiences' with the prototype. The translation between the intentions of the users and the operation of the prototype enabled the session to focus on establishing ways of using computer support in cooperative work instead of focusing on technical aspects of the computer. Furthermore, organisational prototyping strives to elevate the discussion on design and implementation from an operational level of use to an organisational level of organising work, where the issue of tacit knowledge becomes less significant.

Thus, organisational prototyping is possible with even fairly horizontal prototypes when investigating breakdowns in the organisation of work around the computer is of higher priority than investigating breakdowns in the operational aspects of its use. 


\section{Conclusion}

The use of prototypes in design is complicated when addressing CSCW systems because of the distribution of work in time and space. There seems to be a lack of design methods which address the special problems associated with the design and assessment of computer support for cooperative work. This case has shown how organisational prototyping as a combination of prototyping and organisational game can mediate the adoption of CSCW applications within a work setting. The notion of adoption was discussed as both adapting the work practice to the tool and adapting the tool to the work practice. There are clearly different possibilities for changing either of these two sides dependent on the conditions of the application and of the organisation: more possibilities of changing an application exist in the design process than in the tailoring of standard software; and some organisations have wide possibilities of re-organising work, whereas in others work has to conform to certain organisational procedures and rules.

The case has illustrated how design of a project management tool on the one hand and establishing a collective use of it on the other, were done by organisational prototyping. The task of project management, however, might just as well have been supported by standard software like a project management tool, an email system, and an electronic bulletin board system. Nevertheless, the method of organisational prototyping provided the opportunity to deliberately organise the use of such tools in order to support the cooperative work of project management. Hence, we feel that the idea of organisational prototyping as a mutual learning process applies for both adopting standard off-the-shelves applications through tailoring and re-organising work, and as a method for designing and taking into use new systems.

\section{Notes}

1 The quoting was originally in Danish and is translated by the author. The square brackets are used for explanatory notes not said by the participants.

\section{Acknowledgements}

The empirical work was done in cooperation with Martin Broch Pedersen which is gratefully acknowleged. Thanks are also due to the participants from Delta Corporation. Susanne Bødker and the anonymos reviewers of Scandinavian

Journal of Information Systems provided helpful comments on an earlier version of the paper.

\section{References}

Bødker, S. \& K. Grønbæk (1991) Design in Action: From Prototyping by Demonstration to Cooperative Prototyping. In Greenbaum, J. \& Kyng, M.: Design at Work: 
Cooperative Design of Computer Systems, New Jersey, Lawrence Erlbaum Associates, Inc., Publishers.

COMIC-D2.1 (1993) Informing CSCW System Requirements, Lancaster \& Manchester University, Oct.

Ehn, P. \& D. Sjögren, (1991) From System Descriptions to Scripts for Action. In Greenbaum, J. \& Kyng, M.: Design at Work: Cooperative Design of Computer Systems, New Jersey, Lawrence Erlbaum Associates, Inc., Publishers.

Erhlich, S.F. (1987) Strategies for encouraging successful adoption of office communication systems, ACM Transactions on Office Information Systems, 5, p. 340-357.

Greenbaum, J. \& M. Kyng, (1991) Design at Work: Cooperative Design of Computer Systems, New Jersey, Lawrence Erlbaum Associates, Inc., Publishers.

Grudin, G. (1994) Groupware and Social Dynamics: Eight Challenges for Developers. Communications of the ACM, Vol. 37, No. 1, p. 93-105.

Grudin, G. \& L. Palen (1995) Why Groupware Succeeds: Discretion or Mandate? In Proceedings of the Fourth European Conference on Computer Supported Cooperative Work, Klüwer, Dordrecht, p. 263-278.

Grønbæk, K. (1991) Prototyping and Active User Involvement in System Development: Towards a Cooperative Prototyping Approach. Ph.D. Thesis, Computer Science Department, Aarhus University, January 1991.

Kreifelts, T., H. Elke \& Woetzel, G. (1993) Sharing To-Do Lists with a Distributed Task Manager, In Proceedings of the Third European Conference on Computer Supported Cooperative Work, Klüwer, Dordrecht, p. 31-46.

Kyng, M. (1995) Creating Context for Design. In Caroll, J. (Ed.) Scenario Based Design: Envisioning Work and Technology in System Development, New York, John Wiley \& Sons, Inc.

Okamura, K., M. Fujimoto, W.J. Orlikowski, \& J. Yates (1994) Helping CSCW applications succeed: The role of mediators in the context of use. In Proceedings of the Conference on Computer Supported Cooperative Work, ACM/SIGCHI \& SIGOIS, NY, p. 55-65.

Orlikowski, W.J. (1992) Learning from Notes: Organizational issues in groupware implementation. In Proceedings of the Conference on Computer Supported Cooperative Work, ACM/SIGCHI \& SIGOIS, NY, p. 362-369.

Pape, T. \& K. Thoresen (1987) Development of common systems by prototyping. In Bjerknes, G., P. Ehn \& M. Kyng, (Eds.) Computers and Democracy, Aldershot, UK, Avebury, p. 297-311

Trigg, R.H. \& S. Bødker (1994) From implementation to design: Tailoring and the emergence of systematization in CSCW. In Proceedings of the Conference on Computer Supported Cooperative Work, ACM/SIGCHI \& SIGOIS, NY, p. 45-54.

Winograd, T. \& F. Flores (1986) Understanding Computers and Cognition: A New Foundation for Design, Norwood, Addison-Wesley Publishing Company. 